\title{
La difícil reproducción de las familias inmigrantes. ¿Hacia la formación de un proletariado étnico español?
}

\author{
Iñaki García Borrego \\ Universidad de Castilla-La Mancha. Departamento de Filosofía \\ inaki.garciaborrego@uclm.es
}

Recibido: 30-03-2008

Aceptado: 30-09-2008

\section{Resumen}

A partir de los resultados de dos investigaciones empíricas, este artículo propone un recorrido por tres factores determinantes de la vida de las familias inmigrantes: la fragmentación migratoria, las condiciones de vida y las expectativas que los padres depositan en sus hijos. La conclusión que se extrae es que las profundas desigualdades sociales que caracterizan a la incorporación de inmigrantes a la sociedad española pueden condicionar negativamente las trayectorias formativo-laborales de sus hijos.

El artículo se cierra con una revisión crítica de algunos de los enfoques teóricos más utilizados por los estudios sobre familias migrantes e hijos de inmigrantes.

Palabras clave: familia; trayectorias migratorias; hijos de inmigrantes; teoría de la asimilación segmentada; epistemología de los estudios migratorios.

Abstract. The hard reproduction of immigrant families. Towards the formation of a Spanish Ethnic Proletariat?

Based on the results of two empirical research studies, this paper deals with three key issues of immigrant families' life: the migratory fragmentation, their living standard conditions, and the expectations that parents place on their children. The conclusion from this analysis is that the deep social inequalities that characterize the incorporation of immigrants into the Spanish society might determine negatively their children's school and training careers.

The paper ends with a critical review of some of the theoretical approaches more common in the studies about migrant families and children of immigrants.

Key words: family, migratory paths; children of immigrants; segmented assimilation theory; epistemology of migration studies.

\section{Sumario}

1. Trayectorias migratorias y fragmentación familiar

2. Disponibilidad laboral y vida familiar
3. Las expectativas paternas

Conclusiones

Referencias bibliográficas 
Los esfuerzos que realizan las personas procedentes de la periferia de la economía del mundo capitalista por huir de lo que Pedreño (2005) ha definido como la condición inmigrante (es decir, la posición social subordinada caracterizada por la discriminación, la precariedad laboral, el estigma étnico, etc.) encuentran obstáculos muy importantes, más allá de los impuestos por la legislación de extranjería. Ello hace que la reproducción de las diferentes especies de capital que traen consigo (cultural, económico, simbólico, etc.), necesaria para realizar sus proyectos migratorios, suela ser más lenta, ardua e incierta de lo que inicialmente habían previsto. A su vez, esto provoca que, al cabo de cierto tiempo de permanencia en España, sus proyectos migratorios sean reformulados y pasen muy a menudo a situarse en un horizonte intergeneracional. En otras palabras: una vez constatadas las grandes dificultades a que se enfrentan para escapar de la condición inmigrante, muchos de quienes están encerrados en ella cifran sus expectativas de ascenso social en sus hijos, en la posibilidad de que estos accedan a un estatuto de ciudadanía efectivo y disfruten plenamente de las condiciones de vida características de un país desarrollado.

Esa esperanza paterna encuentra un correlato en el conjunto de la sociedad española, quien, de forma ilusoria, separa artificialmente a la llamada «segunda generación» de la primera. Así, mientras que se considera a esta última poco más que mano de obra sobre la que apoyar el crecimiento económico del país, preocupa el devenir de aquella, de cuya «integración social» plena se hace depender el futuro de la cohesión social.

Sin embargo, la investigación social muestra que carece de sentido esta separación tajante entre padres e hijos, pues las condiciones de vida y trabajo de los primeros determinan las condiciones de socialización de los segundos. Por ello, no se puede entender el devenir social de la llamada "segunda generación" sin tener en cuenta la situación de unas familias ${ }^{1}$ cuyas trayectorias migratorias $y$ sociales están marcadas a todos los niveles (laboral, legal, residencial, societario, etc.) por la condición inmigrante.

La literatura sociológica sobre migraciones no siempre ha sabido reconocer la centralidad de las familias en los proyectos migratorios ni comprender a fondo lo que pasa dentro de ellas, pero contamos con algunos estudios iluminadores. En un artículo pionero, Sayad (1979) analizó cómo las contradicciones de los proyectos migratorios paternos y sus ambivalencias hacia la sociedad y las instituciones del país de destino se proyectaban sobre los hijos, lo cual enrarecía las relaciones intergeneracionales. Por esa senda han seguido los trabajos de Hassini (1997) y Zehraoui (1999) entre otros; y a medida que los hijos de los inmigrantes norteafricanos llegados a Francia en décadas anteriores fueron accediendo al mercado laboral, se hizo posible analizar la movilidad social intergeneracional de estas familias. Gracias a estos estudios, sabemos que lo que más contribuye a la prolongación de la escolaridad de los hijos

1. En este texto, los términos familia o grupo familiar se refieren siempre a la familia nuclear, no a la extensa, a la que llamamos grupo de parentesco. 
de inmigrantes es la existencia en la familia de un capital cultural previo a la emigración - o, en su defecto, la realización de un gran esfuerzo familiar para producirlo- y el modo en que este sea movilizado dentro del proyecto migratorio (Zeroulou, 1985; Vallet, 1997).

También la teoría de la asimilación segmentada de Portes y sus colaboradores concede un papel muy relevante a la familia dentro del conjunto de factores que influyen en las trayectorias de los hijos de inmigrantes. Señalan la importancia de la composición familiar para la educación y el control de los hijos, y destacan los efectos que tienen sobre la familia el hecho de que los hijos de inmigrantes se suelen aculturar más rápidamente que sus padres. Según Portes y Rumbaut (2001), esto último puede producir una inversión de roles por la cual los padres pierdan autoridad sobre los hijos, y sean incapaces de mantenerlos alejados de la «subcultura del gueto» presente en muchos de los barrios donde se asienta la población inmigrante.

Por otro lado, el desarrollo del enfoque de género y el auge de la perspectiva transnacional han producido en la última década estudios que combinan ambos acercamientos teóricos de un modo muy fértil. Estos han puesto en un primer plano el hecho de que (casi) todo proyecto migratorio es un proyecto familiar, y que este no puede entenderse sin tener en cuenta las relaciones entre los miembros del hogar y las estrategias diferenciales que estos elaboran para mantener o mejorar sus condiciones de vida ${ }^{2}$.

Aplicando estas aportaciones teóricas al caso español, la hipótesis que se presenta en este artículo es la de que los avatares de las trayectorias migratorias familiares y el modo en que se da la inserción laboral de los inmigrantes inciden negativamente en las posibilidades de ascenso social de sus hijos, situándolos en una posición de clara desventaja respecto a los autóctonos. Para contrastarla, nos apoyaremos en los resultados de dos investigaciones empíricas realizadas en los últimos años en el área metropolitana de Madrid y en la Región de Murcia, dos de los principales polos españoles atractores de inmigración ${ }^{3}$. Siguiendo el desarrollo temporal del proceso migratorio, describiremos, primero, de forma sintética, el proceso de fragmentación y recomposición por el que pasan esas familias, a continuación, analizaremos brevemente el modo de inserción laboral de los padres y, en tercer lugar, veremos cómo las expectativas que estos depositan en sus hijos ocupan un lugar fundamental en los proyectos paternos. En definitiva, el objetivo del artículo es mostrar cómo las relaciones entre padres e hijos llevan las huellas de todo el pro-

2. Una buena muestra de estos enfoques son los estudios recopilados por Bryceson y Vuerela (2002), y en España, los trabajos de Pedone (2003, 2004) y Suárez y Crespo (2007).

3. La primera es una tesis doctoral (García Borrego, 2008) y la segunda, una investigación (coordinada por Pedreño, 2009) en la que participé, realizada en el marco del proyecto TRABIN2 del Grupo Charles Babbage de Investigación en Ciencias Sociales del Trabajo. Ambas fueron llevadas a cabo con una metodología cualitativa. Por limitaciones de espacio, en este artículo se reducen al mínimo la presentación de extractos de las 54 entrevistas en profundidad hechas en total a inmigrantes y a sus hijos. 
ceso migratorio que atraviesa la familia, quedando ésta a su vez indefectiblemente atravesada por él.

\section{Trayectorias migratorias y fragmentación familiar}

La variedad de situaciones por las que pasan las familias migrantes es mucho mayor que la que presentan las no migrantes. Las diversas formas que adoptan hoy en día estas últimas (familias monoparentales, recompuestas, trigeneracionales, unipersonales, etc.), son más corrientes entre las primeras, debido a que los procesos migratorios las someten a tensiones que modifican su estructura. Tensiones de dos tipos principalmente: primero, las derivadas del hecho de que los miembros de esas familias pasan mucho tiempo separados por cientos o miles de kilómetros y, segundo, las provocadas por los avatares de la migración. Para entender esto último, hay que recordar que la emigración e inmigración no es solamente un viaje espacial, sino también una forma extrema de «viaje social», un viaje de una sociedad a otra, o de un punto de la sociedad global a otro generalmente muy alejado de él, lo que implica vivir experiencias complicadas y tener que manejar simultáneamente referentes diversos y a menudo contradictorios.

Para analizar la configuración actual de estas familias, debemos reconstruir sus trayectorias migratorias. Ello entraña dificultades considerables para la investigación, tanto teóricas como metodológicas. Las primeras se deben a la necedad de manejar simultáneamente varias unidades de análisis (los individuos, la pareja, la fratría, la familia nuclear y la extensa) que actúan en procesos de distinta naturaleza (relativos al ciclo reproductivo, a la trayectoria formativo-laboral o a cuestiones íntimas que, a menudo, se ocultan a la persona investigadora). Las dificultades metodológicas se deben a lo difícil que resulta reconstruir las cadenas causales que entrelazan a los procesos migratorios y familiares, pues las formas en que se da la relación entre esas dos esferas son variables y de mutua determinación. A veces, un acontecimiento familiar - por ejemplo: una ruptura de pareja - desencadena un proceso migratorio, de manera que es frecuente encontrarnos con madres de familia que emigraron para combatir la situación de precariedad material en que habían quedado tras separarse de su consorte o ser abandonada por él. Otras veces, por el contrario, lo migratorio precede a lo familiar, y puede ser que la ruptura de la pareja sea consecuencia de los desacuerdos en la forma de gestionar el proyecto migratorio, de las tensiones debidas a las situaciones que hubo que afrontar a lo largo del proceso o de la pérdida de confianza entre los consortes ${ }^{4}$. Pero la cosa se complica aún más por el carácter dinámico y cambiante del proyecto migratorio, que nunca queda del todo definido desde el principio, sino que va reformulándose a lo largo del tiempo. Separaciones que en un inicio se plantearon

4. Por ejemplo, durante los periodos de separación, pueden producirse episodios de infidelidad real o imaginada por los celos (Pedone, 2003). 
como meramente temporales, destinadas a durar unos meses o unos años hasta que la pareja pudiera reunirse, terminaron por convertirse en rupturas firmes. También puede ser que la ruptura se produjese cuando el consorte que inicialmente quedó en el país de origen fue reagrupado, porque, al retomarse la convivencia en España, se pusieron de manifiesto los problemas para reconstruir un proyecto en común, después de todo lo que habían cambiado durante ese tiempo de separación.

A partir del material empírico producido, podemos establecer una tipología básica de trayectorias migratorias familiares:

- Primera trayectoria típica: emigración desde familia de origen. Los padres emigraron cuando aún eran jóvenes solteros ligados a su familia de origen, y posteriormente, ya en España, formaron una familia de reproducción, bien porque conocieron aquí a su futuro consorte o bien porque regresaron a su país para casarse allá y después lo trajeron consigo (como es habitual entre los marroquíes).

- Segunda trayectoria típica: emigración posterior a la formación de la familia de reproducción. Uno de los dos miembros de la pareja emigra y posteriormente reagrupa al otro y a los hijos, si ya los tienen. Puede suceder igualmente que esa reagrupación no llegue a darse, porque la pareja no se recomponga, y se forme otra nueva familia en destino. También es posible que la reagrupación llegue a darse, pero que la pareja no dure mucho tiempo en España.

- Tercera trayectoria típica: emigración tras la ruptura de la familia de reproducción. En algunos casos, tras esa ruptura en origen, al cabo de un tiempo, se forma una nueva pareja en España, y en otros la familia mantiene una composición monoparental.

Estas trayectorias (que el gráfico de la página siguiente representa esquemáticamente) determinan fuertemente las condiciones de socialización de los hijos, ya no sólo por la situación familiar presente, sino porque las dinámicas familiares que se crean a lo largo del proceso migratorio afectan a las relaciones que los hijos establecen con cada uno de los progenitores, con sus hermanos y con los demás parientes, que desempeñan un papel fundamental en el proceso ${ }^{5}$ ¿¿Dónde y con quién se quedaron los hijos mientras la pareja estuvo dividida? ¿Nacieron en el país de origen o en España? ¿Pasaron muchos años separados de sus padres? ¿A qué edad fueron reagrupados? Estas preguntas son claves para entender las trayectorias sociales y las experiencias personales de estos sujetos, así como los modos en que van a construir sus mundos vitales y sus identidades. Y más allá de una pauta común entre los hijos de inmigrantes de nuestra muestra (la existencia de dificultades para realizar una trayectoria aca-

5. «Tanto en origen como en destino, y a lo largo de todas las fases del ciclo migratorio, el contexto de socialización y de cuidado de la población menor se ve profundamente alterado temporal o definitivamente» (Carrasco y otros, 2002). 


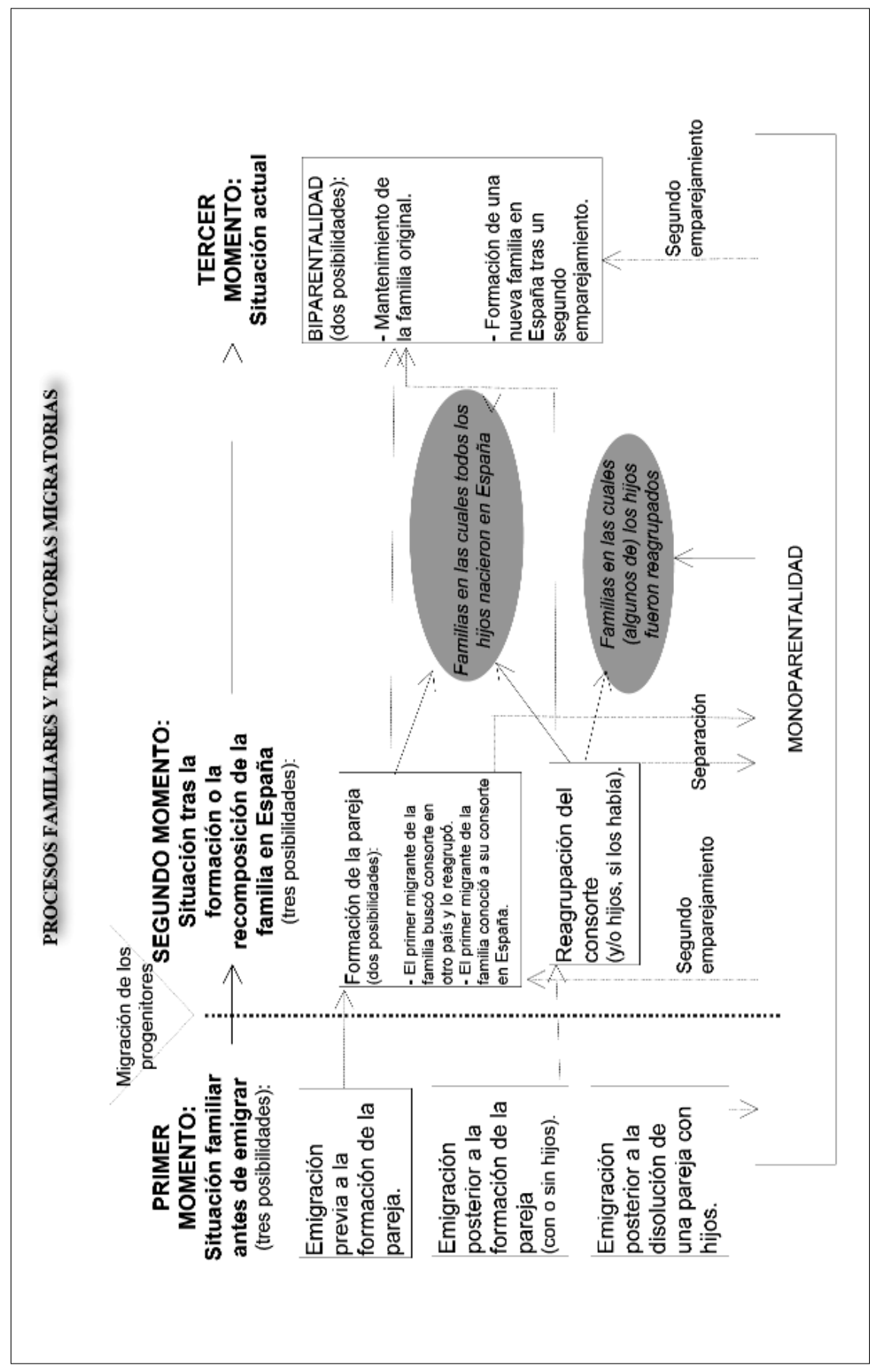


démica prolongada entre quienes fueron reagrupados ya en la adolescencia), las respuestas posibles a esas preguntas son muy diversas, dependiendo de cómo se combinan en cada caso los factores en juego. Por ejemplo, hay sujetos nacidos en España, donde su familia lleva años asentada, para quienes el país de origen no es más que una referencia muy lejana, a pesar de que sus compañeros de clase les identifiquen con él. Y otros que, tras haber sido reagrupados después de largos años separados de sus progenitores, no reconocen la autoridad de estos, lo que puede acentuar los conflictos educativos y las diferencias generacionales entre padres e hijos.

\section{Disponibilidad laboral y vida familiar}

Como es sabido, el hecho de que los inmigrantes no puedan competir en el mercado laboral en igualdad de condiciones con los españoles les orienta hacia los empleos "de difícil cobertura», que si lo son es porque cuesta encontrar trabajadores dispuestos a hacerlos en esas condiciones de trabajo y salario (Cachón, 2002). Ante esa situación, la estrategia que adopta el grueso de los inmigrantes para buscar empleo consiste en estar plenamente disponibles para el trabajo, por lo menos durante sus primeros años de vida en España. Las formas concretas de esta disponibilidad son muy variadas, pero la gran mayoría combinan prácticas de disponibilidad espacial y de disponibilidad temporal. La disponibilidad espacial consiste en desplazarse en busca de oportunidades de empleo, y es precisamente lo que define a las migraciones laborales ${ }^{6}$. La disponibilidad temporal consiste en organizar su tiempo casi exclusivamente en función del empleo, a varios niveles:

- En el ciclo vital: viniendo a España a trabajar con el proyecto de regresar a su país al cabo de unos años.

- En el ciclo anual: permaneciendo once meses al año en España para regresar a su país en vacaciones.

- En el ciclo estacional: trabajando por temporadas en la hostelería o la agricultura, dos ramas muy estacionarias donde abundan los empleos «de difícil cobertura» y que suelen exigir desplazarse a determinadas provincias españolas.

- En el ciclo semanal: trabajando durante el fin de semana o sin descansos de fin de semana.

6. Uno de tantos ejemplos posibles es el de una mujer marroquí de treinta y nueve años, que cuenta por qué vino a España: «Mi hermana vino antes que yo a España y empezó a trabajar en un restaurante, al poco tiempo el jefe le dijo: "Queremos una chica para ayudar en la cocina, si conoces a alguien...". Mi hermana le dijo: "Sí, tengo mi hermana que no habla español y no sabe nada de España, pero trabajar sí es muy trabajadora”. Él dijo: "Bueno, llámala, tráela aquí y vamos a verla un poco". Mi hermana me llamó y me dijo: "Aquí hay trabajo si quieres en el restaurante". Yo le pedí permiso a mi marido, y me dijo: "Bueno, si vas a trabajar..."”. 
- En el ciclo diario: trabajando a cualquier hora, por las noches, sin un horario definido, a destajo, etc. ${ }^{7}$.

Esta extrema flexibilidad espacio-temporal afecta de muchas maneras a los hijos de esos trabajadores. La principal de ellas es el proceso de fragmentación y reagrupación del que ya hemos hablado, que se desarrolla independientemente del curso escolar y que lo interfiere a menudo a nivel anual (incorporaciones tardías al centro docente), estacional (familias que cambian de lugar de residencia durante el curso), semanal y diario (problemas para conciliar las jornadas laborales de los padres con el horario escolar) ${ }^{8}$. Así, los inmigrantes con hijos se enfrentan al mismo dilema que atenaza a muchas familias españolas, sobre todo a las de clases populares: por una parte, deben conseguir los recursos económicos que les permiten mantener unas condiciones de vida aceptables y afrontar los gastos que suponen la crianza y educación de sus hijos; pero, por otra, las exigencias laborales entran en conflicto con las necesidades familiares de cuidar de los hijos y establecer unos ritmos domésticos regulares para adecuarse al curso escolar. En el caso de los padres inmigrantes, que lo tienen más difícil para recurrir a la ayuda de su familia extensa para el cuidado de los hijos?, se da además la paradoja de que es precisamente por sus hijos - como veremos enseguida - por los que hacen ese gran esfuerzo laboral, para que estos disfruten de mejores condiciones de vida, de una buena escolarización y de más oportunidades formativas y laborales que ellos mismos.

Tradicionalmente, la forma más corriente de resolver este conflicto de conciliación entre la vida laboral y familiar pasaba por la división del trabajo entre géneros, pero, con la excepción de los marroquíes, es relativamente raro encontrar familias inmigrantes en las que rija esa división ${ }^{10}$, debido a que actual-

7. La flexibilidad de horarios es también la principal baza con la que juegan muchos comerciantes de origen inmigrante. Para los dueños de esas tiendas de alimentación cada vez más habituales en las ciudades españolas, la única forma de competir con supermercados e hipermercados es precisamente la disponibilidad temporal («Cerramos tarde») y la accesibilidad espacial (comercio de proximidad, "debajo de casa»). Si estas tiendas son cada vez más "comercios étnicos» (chinos en Madrid, pakistaníes en Barcelona, magrebíes en París, turcos en Berlín, etc.), es porque muy pocos españoles aceptarían pasar en su tienda doce horas al día y siete días a la semana para sacar los reducidos márgenes de beneficio que produce el pequeño comercio de alimentación (Riesco, 2003).

8. Un informe del sindicato CCOO (2002) señalaba que uno de los factores que más perjudican al rendimiento escolar de los hijos de inmigrantes es su dificultad para seguir una escolaridad estable y regular.

9. Como se sabe, muchas madres españolas recurren a su propia madre, la abuela de los niños, para que cuide de ellos mientras trabaja, recurso que no está disponible para la mayoría de las madres inmigrantes (Tobío Soler y Díaz Gorfinkiel, 2003).

10. Hay que aclarar aquí que atribuir la inactividad laboral de las mujeres marroquíes a los rasgos patriarcales de las culturas del Magreb sería incurrir en el culturalismo, dado que los estudios realizados en España en los años noventa mostraron que muchas mujeres de ese país ingresaron en el mercado laboral español (Ramírez, 1998; Colectivo Ioé, 2001), especialmente como empleadas de servicio doméstico en las grandes ciudades. En ese nicho laboral permanecieron hasta que fueron sustituidas en él por inmigrantes de otros países, 
mente las mujeres inmigrantes tienen más probabilidades que los hombres de encontrar un empleo en España, lo que hace que el reparto tradicional del trabajo entre géneros no sea una buena estrategia para estas familias, incluso para aquellas que lo practicaban en su país de origen.

\section{Las expectativas paternas}

Los proyectos migratorios son familiares en muchos sentidos, no sólo porque los padres los elaboren muchas veces pensando en sus hijos o porque el desarrollo de dichos proyectos afecte a las relaciones familiares, sino también porque, para movilizar los recursos necesarios para ponerlos en marcha, los migrantes necesitan muy a menudo que sus parientes les ayuden prestándoles dinero, encargándose de sus hijos mientras ellos están fuera o de otras formas. Más adelante, si ese proyecto llega a buen puerto, dichos parientes se beneficiarán directa o indirectamente de ello (recibiendo remesas, aprovechando la posibilidad de ese contacto familiar si ellos también emigran, etc.).

Independientemente de cuál fuese al principio el proyecto migratorio, este cambia de modo inevitable cuando se produce la reagrupación familiar. Una vez que la familia nuclear se recompone - total o parcialmente- en España, los padres deben dedicar parte de su tiempo y de su dinero a cuidar de sus hijos, buscar y mantener una casa donde la familia pueda vivir, un colegio, etc. En ese momento se encuentran en la misma situación que los padres españoles, pues deben decidir cómo organizar la vida familiar en función de los recursos de que disponen en base a tres tipos de posibilidades: tiempo para pasar con sus hijos, dinero para pagar a alguien que se encargue de ellos y relaciones personales para dejarlos con alguien de confianza (una vecina, una amiga o una pariente). Para los inmigrantes, tales recursos suelen ser reducidos. Las palabras de una ecuatoriana residente en Murcia ilustran tanto sobre el lugar central que ocupan sus hijos en los proyectos migratorios como sobre uno de los modos posibles de hacerse cargo de ellos:

Hay una señora que me cuida a la pequeña, pago cien euros por ella. Una marroquina que me la cuida por la mañana. Sólo por írmela a dejar al colegio y traérmela cuando sale. Y le tengo que pagar cien euros. Pues bueno... Tenemos que sacrificarnos un poquín, Por los hijos tenemos que luchar y salir adelante. Son ellos más que nadie... Ya nosotros estamos ya, vamos para... para cuentas para abajo, hacia viejos, muriendo poco a poco... Así que los que quedan son ellos. Pues que queden ellos con cualquier cosa.

Independientemente de cuál fuese la posición social de los migrantes en el país de origen, la condición inmigrante supone a menudo pasar por situacio-

como ecuatorianas y rumanas. Por tanto, la escasa actividad de las procedentes de ese país tiene más que ver con la cultura española (que sigue encerrando al «moro» en un lugar ominoso) que con la magrebí. 
nes en las que hay un riesgo de exclusión social, por lo menos durante sus primeros años en España. Con el paso del tiempo, las familias que logren cumplir sus proyectos migratorios, cuenten con recursos suficientes y se asienten en España podrán acaso superar dichas situaciones, accediendo a condiciones de vida comparables a las de las clases populares integradas en la norma de consumo de masas. Pero es muy probable que ese acceso no se produzca en la primera generación familiar, sino en la segunda, y que sean los hijos quienes puedan dejar definitivamente atrás la vulnerabilidad propia de los primeros tiempos en España. Esto hace que, para estas familias, la movilidad social no sea una cuestión de grado continuo (mayor o menor estatus, mejores o peores condiciones de vida), sino de estados discontinuos (inclusión frente a exclusión) separados por un umbral simbólico. Ese umbral aparece a menudo en sus discursos mediante la expresión «ser algo»:

— ¿Y su hija la pequeña quiere estudiar, qué quiere ser de mayor?

-Aunque no quiera, la vamos a obligar, porque ella es la pequeña y tiene la oportunidad de ser algo, tener un trabajo digno... Aunque no quiera, hay que obligarla.

Si para muchos españoles de las clases populares «ser alguien (en la vida)» significa ostentar algún rasgo distintivo (generalmente un estatus profesional), para los inmigrantes se trata de algo más básico: adquirir un reconocimiento social mínimo que permita huir de la condición de inmigrante. Para este grupo social, la frontera entre ser algo y no ser nada tiene un carácter casi absoluto, pues marca un límite inferior por debajo del cual sólo está la pura subsistencia material y la carencia de cualquier identidad social distinta de la de inmigrante anónimo, mano de obra a la que se retribuye con el salario mínimo necesario para reproducir su fuerza de trabajo simple.

«Mi hermana pequeña tiene que seguir estudiando para ser alguien, para llevarse un trabajo bueno, para tener un futuro bueno", decía un joven marroquí entrevistado, que, tras haber sido reagrupado a una edad tardía, no había podido proseguir sus estudios. Como hermano mayor de cinco, sus expectativas estaban depositadas - igual que las de sus padres - en los hermanos menores, quienes, gracias al esfuerzo migratorio paterno, habían disfrutado de mejores condiciones de vida durante su infancia. A menudo, lo que esperan los adultos de sus hijos y hermanos menores es que borren simbólicamente el origen inmigrante de la familia, lo que no significa que oculten a sus rasgos etnoculturales distintivos, sino que lleguen a «ser algo». Como veremos a continuación, un caso particular que lo ilustra es el de quienes pertenecían a las clases medias de su país, origen frecuente entre los ecuatorianos procedentes de zonas urbanas. Para ellos se trata, además, de reconquistar el estatus perdido, con lo cual deben invertir el proceso de desclasamiento que les empujó a emigrar. 


\section{El caso de Carla}

Un buen ejemplo de esto es el caso de Carla, una adolescente ecuatoriana de diecisiete años llegada a España a los trece. Carla es la menor de una familia extensa compuesta por dos núcleos, ambos residentes en Murcia: uno formado por ella y sus padres (comerciantes en Quito, ahora trabajadores del campo), y el otro formado por su hermana mayor (maestra en Quito, ahora encargada de una tienda), su marido (ahora transportista) y el hijo de ambos, de doce años. Los padres de Carla siempre apostaron fuerte por la educación de sus hijas ${ }^{11}$. Las escolarizaron en colegios privados hasta que su negocio quebró por la crisis que afectó al Ecuador a finales de los noventa. Para entonces, la hermana mayor ya estaba trabajando en Murcia, y fue ella quien sugirió la posibilidad de que Carla se reuniera con ella para proseguir sus estudios en España. Los padres aprobaron la idea y decidieron que, en vez de enviar a Carla sola a reunirse con su hermana mayor, lo mejor era venirse ellos también a España ${ }^{12}$. Ello les permitiría seguir supervisando de cerca la escolaridad de Carla, temerosos como estaban de que la chica se viese afectada por el ambiente de indisciplina que, según les había contado su hija mayor, reina en las aulas españolas. Piensan regresar a Quito una vez que su hija termine los estudios (en sus propios términos, «corone»). Actualmente, Carla cursa bachillerato tecnológico, quiere estudiar ingeniería y va bastante bien en los estudios, aunque hay dos asignaturas importantes en esa especialidad con las que tiene dificultades, por lo que sus padres han contratado a un profesor particular. Ella es consciente de las expectativas familiares que pesan sobre su carrera académica y trata de responder a ellas:

-Dices que vas a ir a la universidad...

-Digo, sí, pero no sé, ya no sé...

- Pero lo estás intentando.

- Sí, yo lo estoy intentando y hago todo lo posible, y voy a hacer todo lo posible para ir a la universidad, eso sí.

- Ypor ahora vas bien.

- Sí, aunque se queda suspensas dos asignaturas, pero yo eso lo tengo que sacar como sea.

[...]

—Tus padres dices que son estrictos...

- Sí, son muy estrictos mis padres, porque, no sé, son así sus costumbres, no sé.

— Con los estudios?

—-También, a mi por lo menos me dicen: «Si no estudias, ya sabes,

11. Hablando de la primogénita, dice su madre: «Ella sí llegó a coronar, ella tiene la universidad, mi hija la grande, ella podía, pero después se enamoró del marido, se casó, hay que ver, cuando ya casi estaba ella a punto de...».

12. "Nosotros más estamos aquí por ella, que todavía no ha terminado el estudio, y en la situación que estábamos allá era difícil, no le podíamos pagar la universidad, ni el mismo colegio en que estaba allá.» 
te vas a la lechuga». Normalmente siempre me dicen eso, si yo no estudio, me voy al campo a recoger lechugas, porque no sé, yo creo que como cualquier padre, ¿no? quiere lo mejor para su hijo, y quiere verle que llegue a ser alguien en la vida con un título, yo qué sé, ilusiones que se hacen [ríe]. Entonces yo trato pues, de darles ese gusto.

- ¿Qué es lo que hacen ellos para animarte, presionarte o lo que sea?

- ¿Para animarme? Pues mira, la presión que ahora tengo es que toda mi familia me está esperando en Ecuador, y que supuestamente si apruebo todo, pues este verano viajo para allí. Pero dicen claro: «Si suspendes o te queda algo, no te vas, te quedas aquí estudiando"; y esa es la presión que te meten.Yo qué sé, a veces te hacen regalos, no sé, a veces te dicen: «Es que me gustaría verte que seas alguien», cosas así, no sé.

- Pero a ti te va bien en los estudios, ¿no?

-Sí.

- ¿Y alguna vez te han castigado porque no estudies o porque...

- No, no, a mi no me han castigado, a mi simplemente me dicen que ya eso es cuestión mía, que si yo quiero estudiar, que estudie, y si no, pues que ya vaya a encontrar un trabajo; pero castigarme, no.

En muchas familias de origen inmigrante, los hermanos mayores supervisan la escolaridad de los pequeños, sobre todo cuando los padres no pueden hacerlo por alguna razón: por estar ausentes, por su horario laboral, porque no saben español o no conocen el sistema educativo... La hermana mayor de Carla está muy implicada en la tarea de ayudarle a sacar adelante su proyecto académico. Pero lo singular del caso es que no lo está en sustitución de sus padres, sino en colaboración con ellos, reforzando el seguimiento que estos hacen, tarea para la cual la hermana está especialmente cualificada, dada su formación y su experiencia como maestra en Ecuador. Este esfuerzo conjunto de los padres (sobre todo la madre) y la hermana mayor acentúa el carácter de proyecto familiar que tiene la carrera académica de Carla. Dice su hermana mayor:

En Ecuador, mi hermana era una de las mejores estudiantes, tanto de la escuela como del colegio era muy buena, siempre se ha destacado, de iniciativa muy buena, pero cuando llegó aquí el primer año muy bien, el segundo año también, entró en el instituto y empezó a bajar un poquito [...]. Ella dice: «Ustedes no comprenden que la carrera que yo he cogido es muy difícil, muy fuerte»; y yo le digo entonces — y mi marido también se lo dice--: «Nosotros comprendemos, pero sabemos que tú eres muy capaz, que tú eres bien inteligente y puedes, lo que pasa es que te dejas, tú te dejas un poco...». Pero en la casa está dedicada, tú la ves siempre en su habitación, estudiando con sus cuadernos. La hacen llorar mucho en dibujo técnico y me parece que es la química o la física, una de las dos, que la hace llorar, pero es buena estudiante... De vez en cuando se afloja y hay que estar insistiendo. Ella lo hace todo sola, pero a veces hay que estar: «No te vayas a olvidar de esto, dedícate un poco más», y ella: «Ya, ya lo sé, si lo hago, pero es que ya no puedo, no sé qué pasa, parece que mi cabeza, como que cada vez que pasan los años se me atrofia 
algo». Y yo le digo: «No se te atrofia nada, es que el tiempo que tienes libre dedícalo a eso, dedícalo a aquello que estás fallando, dedícate un poco más». «Es que me cansa», me dice... Pero es buena, no nos quejamos, es buena estudiante, pero sí que puede dar más, pero no quiere dar más.

La familia de Carla espera mucho de ella — vemos que hasta su cuñado trata de reforzar su motivación-y la somete a una fuerte presión («El tiempo que tienes libre dedícalo a eso, dedícalo a aquello que estás fallando, dedícate un poco más»). Esas expectativas son tales que la familia parece no reparar en las dificultades de la empresa: primero, tener que adaptarse al sistema educativo de un país desconocido y, segundo, tener que afrontar la discriminación de sus compañeros:

[Venir a España] es un cambio, muchísimo, tú estas acostumbrado a que en las clases no se hable, ni se diga nada, porque allí en Ecuador los maestros son muy estrictos en la disciplina [...] Aquí sí hay indisciplina, hay falta de respeto muchas veces a los maestros, a veces surgen problemas y me quedo un poco admirada, pero luego ya te terminas acostumbrando, lo que no tienes que hacer es seguir los mismos ejemplos de los demás.

$[\ldots]$

Siempre hay eso del racismo, pero igual yo me enfrentaba a todo, y yo qué sé, aquí en el pueblo pues, no, tampoco es que me guste esto, ¿̇no? Es un pueblo muy pequeño, yo soy de Quito, de la ciudad, y yo qué sé, esto de los pueblos y tal... Pero bueno, poco a poco ya se va uno acostumbrando a las costumbres y todo, y... También tuve un percance, con..., cuando empecé en el instituto, porque hay, había un muchacho racista, como siempre, y pues no sé, a mi no me conocía de nada, y quiso pasarse conmigo, y yo, como tengo el carácter un poco fuerte pues no pudo. [...] Siempre hay algo, alguien [que dice:] es que los ecuatorianos no sé qué, pues entonces te sientes un poco mal ¿no? Porque tú eres ecuatoriano... ¿Pero por qué no me pueden llamar por mi nombre? [...] Tú vas caminando en la calle y los mismos del instituto te ven, y por cualquier cosa te dicen: «Ecuatoriana de mierda», entonces tú también pues le empiezas a contestar, entonces empieza a haber roce ahí.

\section{Reajustes en las expectativas paternas}

Ya hemos visto que el cumplimiento de las expectativas paternas depositadas en la escolaridad de sus hijos se enfrenta a obstáculos considerables. Por ello, no es raro que, a medida que pasa el tiempo y esas dificultades se van haciendo patentes, los padres vayan reajustando sus apuestas escolares en función de los resultados académicos obtenidos. Además, la posibilidad de hacer apuestas a medio o largo plazo se ve muy limitada por la necesidad de hacer frente a las exigencias cotidianas de la vida familiar, marcadas por la disponibilidad laboral de la que hablábamos más arriba. Por ejemplo: unos padres pueden querer que su hija llegue a la universidad, pero al mismo tiempo encargarle que vaya todos los días a recoger a sus hermanitos del colegio, les prepare la merienda, 
les ayude a hacer los deberes y cuide de ellos hasta que su madre vuelva a casa por la noche. Si en algún momento perciben que dichas tareas afectan a sus estudios, tendrán que elegir entre renunciar a su sueño universitario u organizar la vida familiar de otro modo, si es que tienen posibilidades de hacerlo. Finalmente, muchos padres pueden considerar que no tiene sentido albergar grandes expectativas cuyas probabilidades de cumplirse son escasas, y prefieren hacer apuestas menos ambiciosas, como la de que sus hijos alcancen un estatus social aproximadamente equivalente o sólo algo superior al suyo.

Por una razón u otra, lo cierto es que, en las entrevistas con los padres, a menudo aparecen elementos que apuntan a los límites del apoyo paterno a la prolongación de los estudios de sus hijos. Estos límites remiten a diferentes circunstancias familiares. Veamos tres ejemplos, dos de familias ecuatorianas y un tercero de una marroquí. El primero de ellos es el de una madre de tres hijos, quien, después de mencionar varias veces a lo largo de la entrevista los efectos sobre su salud de la dureza de su trabajo en un invernadero (fatiga crónica, calambres y dolores musculares), explica que no deja ese trabajo porque la familia necesita su sueldo para pagar la hipoteca de la casa que acaban de comprar, y dice:

Yo trabajo obligada. Hago esto porque, si no trabajo, sólo con el trabajo de mi marido no alcanza el sueldo, así que tengo que trabajar yo también, entonces... Ahí estamos, hasta que Dios me dé fuerzas. Yo no le pido nada más que me dé fuerzas y salud, para poder salir adelante y pagar esto. Ya trabajará mi hijo para que yo pueda... Para yo no trabajar más. Yo les digo [a sus hijos mayores, de diecisiete y dieciséis años]: «Ustedes tienen que ir a trabajar, para yo ya descansar». Pero bueno... Esperemos unos dos años más siquiera, tres años... Para yo descansar. Que todavía no estoy..., vieja, que diga. Pero es matador trabajar en el campo.

El segundo ejemplo es el de otra mujer ecuatoriana, quien considera que su hija, actualmente estudiante universitaria, debería incorporarse pronto al mercado laboral:

\section{- ¿Ustedes le pagan los estudios a su hija, o ella también trabaja?}

- Sí trabaja, echa unas horitas limpiando aquí a un señor abajo, y nosotros también ayudamos en lo que podemos, hasta que podamos ayudarle lo haremos, o hasta que ella también se busque su vida, porque tiene edad de buscársela, y de trabajar ya.

Habitualmente, cuando los padres manifiestan a sus hijos que el apoyo a la prolongación de sus estudios tiene un límite, estos últimos lo interpretan en términos afectivos, relativos a la relación paterno-filial, sobre todo cuando reciben mensajes contradictorios por parte de diferentes miembros de su familia. En el caso de la primera de las dos madres citadas, su discurso quejoso contrastaba vivamente con el de su marido, que gozaba de mejor estado de salud y tenía proyectos más ambiciosos, entre los cuales ocupaban un lugar destaca- 
do los relativos al futuro profesional de su primogénito. Por su parte, la hija de la segunda familia ecuatoriana mencionada se sentía más apoyada por su padre (que le decía que se dedicase plenamente a estudiar sin ocuparse de nada más) que por su madre, quien, como acabamos de ver, creía que ya tenía edad de trabajar. Finalmente, tenemos también el ejemplo de una adolescente marroquí, quien ha convertido la falta de apoyo de sus padres a sus estudios en un acicate para demostrarles que merece la pena apostar por su proyecto académico, algo que sí hace en cambio su hermana mayor residente en Marruecos, que no pudo ser reagrupada por ser mayor de edad:

- ¿Tus padres te animan a que sigas en el instituto y estudies?

- Bueno... Bueno, mi padre cree que no soy capaz de sacar nada, porque dice: «En España, tú no vas a poder sacar nada, porque no sabes el idioma...». Y bueno yo siempre hago esfuerzo para demostrarles que sí que puedo. si puedes?

- YY en cinco años que llevas aqui estudiando, se han convencido ya de que

- Sí, pero a veces dicen: «El bachillerato no vas a poder sacarlo», así que tú siempre tienes que hacer fuerza para demostrarles que sí.

_ ¿Ellos miran tus notas? ¿Se enfadan si has suspendido algo?

-No, no enfadan, no les importa, no enfadan ni nada, es que me dicen: «Son tus problemas, tú sabes porque ya eres adulta, tú estás ya responsable de ti misma». [...] En Marruecos siempre me decían que hay que sacar, tienes que sacar bien y tal, tienes que estudiar, pero aquí ya no.

[...] diez años?

—iTú qué crees que a tus padres les gustaría que hicieras de mayor, dentro de

- Pues no sé, mi padre quiere que haga un curso, algún módulo, no quiere que siga estudiando, porque mi hermana ya ha estudiado mucho, y mis padres ya están viejos, ya sabes... Quieren que haga un módulo, yo quería estudiar, profesora de matemáticas o de francés, pero no quieren ellos.

[...]

- ¿Y quien dirías que está así como más preocupado por lo que tú hagas?

- Mi hermana... Está siempre preocupada de todos los hermanos, siempre llama por teléfono y pregunta las notas: «¿Qué has sacado? ¿Cómo vas?». Siempre le dice también a mi hermano que tiene que estudiar, coger aquí su diploma para ir a trabajar en Marruecos, que ella le ayudará a buscar un trabajo bueno allí.

\section{Conclusiones}

\section{¿Hacia la formación del nuevo proletariado étnico?}

Los hijos de inmigrantes se hacen mayores en medio de un complejo proceso migratorio que determina el grado de fragmentación de la familia original e impone ausencias que modifican las dinámicas familiares, por ejemplo, reduciendo sus posibilidades de pasar tiempo acompañados por personas mayores que les dediquen un tiempo, cuiden de ellos, supervisen su escolaridad y les apoyen en ella. Por otro lado, el modo de inserción laboral de los padres pone 
cortapisas a la vida de las familias, por partida doble. En primer lugar, como emigrantes que salieron de su país: cuando uno de los miembros de la pareja de padres se va a trabajar al extranjero, se desencadena en origen un proceso de profunda reconfiguración, que afecta de forma irreversible al ciclo reproductivo y puede resultar desestructurante ${ }^{13}$. $Y$, en segundo lugar, como inmigrantes insertados en el sistema productivo español en empleos que imponen largas jornadas y horarios intempestivos a cambio de bajos salarios, y que a menudo implican situaciones de precariedad e incertidumbre que impiden formular proyectos a medio y largo plazo. Por todo ello, son estas familias las que sufren de forma más intensa las tensiones provocadas por la actividad laboral de sus miembros, tensiones que pueden dar lugar a expectativas paternas poco realistas respecto a la escolaridad y al futuro de sus hijos, y desembocar en agudos conflictos personales o familiares.

Si pensamos en cómo todos estos elementos determinan las condiciones en que se socializan los hijos de inmigrantes, no es difícil entender que lo que más les diferencia de los españoles de su grupo de edad no es esa supuesta «doble cultura» o "doble identidad» sobre la que se suele insistir demasiado, sino la posición generacional que ocupan en familias inevitablemente afectadas por esta combinación de factores. Incluso aquellas familias que están ya muy asentadas en España, y que disfrutan de derechos de ciudadanía y de unas condiciones de vida equiparables a las de los españoles de clases populares, llevan, de una forma u otra, las huellas de todas las dificultades que debieron ser superadas para llegar hasta ahí. Sabiendo que la familia actúa como un mecanismo de reproducción de la estratificación social (pues cada generación familiar transmite a la siguiente lo que tiene, y no puede transmitirle aquello de lo que carece), resulta ilusorio pensar que las profundas desigualdades que caracterizan a la incorporación de inmigrantes a la sociedad española van a desaparecer sin dejar rastros en la siguiente generación familiar como por arte de magia, o gracias a la acción de un sistema educativo que no cuenta con los recursos necesarios para operar ese milagro social. Los datos de que disponemos ya sobre su escolaridad (con tasas de fracaso escolar superiores a las de los autóctonos) y su precaria inserción laboral no invitan a hacer pronósticos optimistas, sino que apuntan en la dirección señalada por Pedreño (2005): podríamos estar asistiendo a la formación de un proletariado étnico, cuyos miembros no serían ya inmigrantes extranjeros, sino españoles de origen inmigrante ${ }^{14}$.

Una cuestión altamente determinante de las trayectorias de los hijos de inmigrantes es la de en qué medida las condiciones en que se desarrolla el proce-

13. Esto vale también, incluso con más motivo, para las monoparentales. En este artículo no nos hemos ocupado de la problemática en origen de las familias migrantes, sobre la que pueden consultarse los trabajos de Herrera y Martínez (2002), Pedone (2003) y Sørensen (2004).

14. Cachón (2005: 57) dice que los inmigrantes jóvenes son «los más obreros de la clase trabajadora», y Arango (2004: 172) habla de una «nueva clase trabajadora». Entre los numerosos trabajos que aportan — de forma directa o indirecta — indicios de esta tendencia, podemos citar los de Cachón (2003), Domingo y Bayona (2007), y Riesco y Carrasco (2008). 
so migratorio familiar permiten reproducir los capitales ligados a la posición social en el pais de origen, y si el entorno en que se ha desarrollado ese proceso ha facilitado o dificultado dicha reproducción (entorno de varios niveles concéntricos, desde el más local e inmediato hasta las grandes tendencias sistémicas que marcan el devenir de la economía del mundo capitalista). De ello depende en gran parte la gran variedad de situaciones en que se encuentran y de trayectorias que siguen los integrantes de ese grupo de población. Que dicha variedad sea tan grande que resulte muy difícil hacer generalizaciones o diagnósticos globales no debe llevarnos a creer que ello no es posible o carece de sentido, pues aunque los factores que definen la situación particular de cada hijo de inmigrantes puedan combinarse de un modo distinto en cada caso, la investigación social ha mostrado que, estructuralmente, son siempre los mismos. Metafóricamente, podemos decir que las cartas pueden estar barajadas de muchas maneras, pero son siempre las mismas, y sólo hay cuatro palos y tres figuras en la baraja. Y si esa variedad parece remitir a una cuestión de meras diferencias entre colectivos nacionales, es sencillamente porque la variable "país de origen» oculta todo el conjunto de elementos que confluyen, en un momento dado de la historia de un país, para determinar por qué algunos de sus habitantes emprenden el camino de la emigración y otros no, qué grupos sociales emigran a unos sitios o a otros, en qué condiciones lo hacen, etc.

\section{Ritornelo: algunos elementos para un debate teórico}

Los resultados que acabamos de presentar permiten retornar ahora sobre algunas de las cuestiones teóricas presentadas en la introducción del artículo, en diálogo con los autores cuyas ideas movilizamos para llevar a cabo nuestras investigaciones. La lectura de Sayad (1979) nos permitió darnos cuenta de dos cosas fundamentales: que detrás de todo inmigrante que llega a un país hay un emigrante que salió de otro con un proyecto, y que sus hijos heredarán esa doble condición social, la anterior y la posterior a la migración, junto con las contradicciones de dicho proyecto. E igual que Sayad analizó cómo la vida familiar de los magrebíes asentados en Francia estaba atravesada por la dominación neocolonial, los nuestros deben tener en cuenta los nuevos rasgos definitorios del sistema migratorio europeo actual (diversidad de orígenes, proyectos y trayectorias migratorias, nuevas relaciones entre el centro y la periferia dentro de un proceso de reestructuración económica global, etc.), muy distintos de los que él estudió.

Pasando ya a los trabajos realizados con una perspectiva transnacional, les debemos el gran aporte que supone incorporar al análisis de los procesos migratorios aspectos fundamentales, que otros enfoques más «naciocéntricos» no pueden dilucidar. Ahora bien, cabe señalar que, en ocasiones, ello se hace soslayando el análisis de los espacios sociales nacionales, regionales y locales, relegando a estos a un plano secundario, como si por ser su ámbito geográfico más reducido los factores que actúan en ellos fuesen menos determinantes. Esto empobrece inevitablemente el análisis, puesto que lo que sucede en realidad 
es justamente lo contrario: que son los factores que actúan en espacios más restringidos los que ejercen sus determinaciones de un modo más directo e inmediato. Por ejemplo: si las estrategias transnacionales que despliegan los migrantes son una forma de sortear los obstáculos que encuentran al entrar en contacto con las instituciones nacionales, regionales o locales del país de destino, antes de dar por supuesta la presencia permanente de dichos obstáculos hay que ver cómo actúan ${ }^{15}$. En definitiva, creemos que el análisis de los factores transnacionales no puede sustituir el de los que actúan en ámbitos territoriales menores. De lo que se trata es de articularlos todos, construyendo dialécticamente modelos teóricos que incluyan los múltiples ámbitos en que se estructuran las relaciones sociales. No tiene sentido proscribir el uso del término inmigrantes y sustituirlo sistemáticamente por el de migrantes en aras de la superación del nacionalismo metodológico, pues dependiendo de qué aspecto de ese proceso multifocal que son las migraciones queramos iluminar, puede ser más esclarecedor hablar de emigrantes, de migrantes o de inmigrantes.

El enfoque de género permite abrir la caja negra del proyecto migratorio familiar, mostrando que este no tiene las mismas implicaciones para cada uno de los miembros de la familia, puesto que tampoco son iguales las posiciones que estos ocupan dentro de ella, ni su grado de acceso al mercado laboral, la carga de trabajo reproductivo que asumen, las relaciones con los otros parientes, etc. Todas estas diferencias y desigualdades dan lugar a proyectos y estrategias migratorias distintas o incluso opuestas ${ }^{16}$, como se hace patente en esta entrevista que realizamos a una familia marroquí asentada en Murcia:

-Y la decisión de reagrupar, ¿cómo fue?

- [Hija:] Fue de mi madre, porque mi padre no quería.

- $[\mathrm{Al} \text { padre: }]_{¿}$ Usted no quería?

- [Padre:] Yo trabajo mucho, y dinero poco. Mucha familia aquí.

- [Hija:] Él sabía que no va a gustarnos aquí, por eso no quería reagruparnos, pero mi madre, quería mucho porque sabe bien que no vamos a vivir bien en Marruecos.

—[Al padre:] ¿Usted qué pensaba entonces?

—-[Padre:] Mejor yo trabajo aquí solo, y dinero... [Habla en marroquí].

—[Traduce la hija:] Mandar dinero allí. Él quería intentar asentarse aquí y ganar mejor, pero mi madre quería que todos estamos aquí.

Sin embargo, el énfasis que hacen los estudios realizados con un enfoque de género en que los proyectos migratorios de mujeres y hombres son general-

15. Basta justamente con constatar lo difícil que resulta sortear dichos obstáculos para darse cuenta del gran poder que aún concentran los estados nacionales como agentes reguladores de las relaciones sociales, papel regulador que a veces no tienen en cuenta los estudios transnacionales.

16. Pedone (2003) aporta numerosos ejemplos de esto, y Suárez y Crespo (2007: 243) llegan al punto de considerar que, puesto que es así, resulta engañoso tomar al grupo familiar como unidad de análisis. 
mente distintos, no debe hacernos olvidar un hecho igualmente cierto: que, como se atisba en este extracto de entrevista, aunque las negociaciones entre los miembros del grupo familiar se hagan en condiciones de desigualdad de género, los miembros de la pareja llegan muy a menudo a consensos, desarrollan proyectos unitarios y elaboran estrategias conjuntas para alcanzar objetivos compartidos que, si se logran, pueden beneficiar — en igual medida o noa todas las partes.

Hemos querido dejar para el final de esta sección de discusión teórica la teoría de la asimilación segmentada de Portes y sus colaboradores, en razón de la difusión que ésta está alcanzando en España. Lo primero que hay que decir de ella es que supone un logrado esfuerzo de articulación de los principales factores que determinan, combinándose de forma compleja, las trayectorias de los hijos de inmigrantes. Pero acaso se deba a ese esfuerzo abarcador el que sean tratadas de forma un tanto esquemática cuestiones de gran importancia, que, si bien aparecen mencionadas en el libro de Portes y Rumbaut (2001), no son del todo bien abordadas e incorporadas al análisis, suficientemente sistematizadas o resueltas de un modo convincente. Por señalar únicamente los dos conjuntos de factores cuyo tratamiento nos parece más deficiente ${ }^{17}$ :

- La importancia de los proyectos migratorios sólo es mencionada de pasa$\mathrm{da}$, sin investigar las trayectorias migratorias de las familias ni sus configuraciones actuales, más allá de una distinción dicotómica muy básica sobre si actualmente es biparental o monoparental. El olvido de la historia familiar (en sus dos dimensiones complementarias: subjetiva - proyectos- $-\mathrm{y}$ objetiva - trayectoria-) se debe, a nuestro entender, al nacionalismo metodológico que contamina su estudio, cuya principal pregunta de investigación es la de si los hijos de inmigrantes se «asimilarán» a la sociedad estadounidense ${ }^{18}$. Así, al analizar a las familias migrantes en su "aquí y ahora», como si hubieran empezado a existir en el momento en que se asentaron en los EE. UU., renuncian —olvidando las enseñanzas de Sayad—a entender

17. Dejamos aquí de lado las objeciones epistemológicas que podrían hacerse respecto a la «racionalidad metodológica empírico-analítica» (la expresión es de Beltrán, 1988: 328) en que se inscribe esta teoría. Digamos solamente que, a falta de una construcción sólida de su objeto de estudio, Portes y Rumbaut (2001) manejan acríticamente ciertas prenociones ideológicas propias de la sociología espontánea estadounidense, tales como «americanización», "underclass» y "American mainstream», sobre las que apoyan sus argumentos como si fueran conceptos de las ciencias sociales. Sobre los presupuestos ideológicos de la sociología de las migraciones estadounidense y el lugar que ocupa en ella la teoría de la asimilación segmentada, ver García Borrego (2006).

18. «This book concerns a phenomenon that has not yet moved to center stage but whose transformative potential, for better or worse, is immense. [...] Whether this new ethnic mosaic reinvigorates the nation or catalyzes a quantum leap in its social problems depends on the forms of social and economic adaptation experienced by this still young population» (Portes y Rumbaut, 2001: XVII). 
hasta qué punto su situación actual y sus trayectorias potenciales se deben a su devenir pasado, y evacúan el horizonte transnacional en que muchas veces se inscriben sus prácticas.

- Portes y Rumbaut establecen una relación de causa y efecto entre la aculturación disonante (es decir, el hecho de que los hijos se aculturan más rápidamente que los padres) y la inversión de roles, y hacen de esa secuencia el principal motor de los conflictos familiares. Al plantearlo así, de forma un tanto lineal, incurren a nuestro entender en cierto culturalismo, pues atribuyen a cuestiones culturales algo que puede tener más que ver con otros factores analizados en este artículo: el lugar que ocupan los hijos en los proyectos paternos y las expectativas depositadas en ellos, el modo en que las trayectorias migratorias y la inserción laboral de los padres afectan a las dinámicas y configuraciones familiares, o la situación de vulnerabilidad en que se encuentran muchas de estas familias.

El hecho de que los estudios sobre migraciones carezcan en España de tradición sociológica no debe llevarnos a aplicar acríticamente a nuestro objeto de estudio modelos teóricos creados en otros países, que pueden ser apropiados para ellos, pero no la realidad española actual. Si resulta obvio que el marco de análisis brillantemente desarrollado por Sayad en la Francia neocolonial de la década de 1970 debe ser adaptado mutatis mutandis al caso español de principios del siglo XXI, lo mismo pasa con la teoría de la asimilación segmentada. Esta es un dispositivo teórico muy potente para el estudio del caso estadounidense, pero resulta difícilmente aplicable a un país como España, al menos en su formulación actual. Para que esa aplicación sea fructífera, deben reajustarse, a nuestro entender, como mínimo tres de los parámetros fundamentales de dicha teoría, relativos a sendas diferencias entre la sociedad estadounidense y la española: los respectivos sistemas de organización de la diversidad etnorracial; la escasa extensión y antigüedad aquí de redes o "comunidades» etnonacionales, y la inexistencia de una "subcultura del gueto» comparable a la de las ciudades estadounidenses, tan diferentes a las europeas a ese respecto (Wacquant, 2001). El árbol de la ciencia sociológica puede crecer en los más diversos climas, pero debe trasplantarse con cuidado.

\section{Referencias bibliográficas}

ARANGO, J. (2004). «La inmigración en España a comienzos del siglo XXI». En: FUNDACIÓN FERNANDO ABRIL MARTORELL: Informe sobre la situación demográfica en España 2004. Madrid: Fundación Fernando Abril Martorell.

Beltrán, M. (1988). Ciencia y sociología. Madrid: Centro de Investigaciones Sociológicas.

BRYCESON, D.F. y Vuerela, U. (2002) (eds.). «Transnational families in the twentyfirst Century». En: The Transnational Family: New European frontiers and global networks. Oxford (UK): Berg.

CACHÓN, L. (2002). «La formación de la "España inmigrante": mercado y ciudadanía». Revista Española de Investigaciones Sociológicas (REIS), 97, 95-126. 
- (2003). Inmigrantes jóvenes en España: Sistema educativo y mercado de trabajo. Madrid: Instituto de la Juventud (Ministerio de Trabajo y Asuntos Sociales).

- (2005). «Inmigrantes jóvenes en España». En: LópEZ BLASCO, A. y otros: Informe Juventud en España 2004: Condiciones de vida y situación de los jóvenes. Madrid: Instituto de la Juventud.

CARrasco, S. y otros (2002). «Sobre infancia e inmigración: Consideraciones teóricas y metodológicas desde un informe de la situación en Barcelona». Actas del III Congreso sobre la Inmigración en España, vol. II. Granada: Universidad de Granada.

CCOO (2002). Cuadernos de información sindical: La escolarización de los hijos de inmigrantes en España, II. Madrid: Confederación Sindical de Comisiones Obreras.

COLECTIVO IoÉ (2001). Mujer, inmigración y trabajo. Madrid: IMSERSO.

Domingo, A. y BAYONA, J. (2007). «Perfil sociodemográfico de los jóvenes de nacionalidad extranjera en España y en las islas Canarias» En: CACHÓN, L. y LÓPEZ SALA, A. (coords.): Juventud e inmigración: desafios para la participación y la integración. Sta. Cruz de Tenerife: Consejería de Empleo y Asuntos Sociales del Gobierno de Canarias.

GARCíA BorREGO, I. (2006). «Generaciones sociales y sociológicas: un recorrido histórico por la literatura sociológica estadounidense sobre los hijos de inmigrantes». Migraciones Internacionales, 11, 4-34.

- (2008). Herederos de la condición inmigrante: adolescentes y jóvenes en familias madrileñas de origen extranjero. Madrid: Universidad Nacional de Educación a Distancia. Tesis doctoral inédita, disponible en: http://e-spacio.uned.es/fez/view.php?pid =tesisuned:CiencPolSoc-Igarcia (22-03-2009).

Hassini, M. (1997). L'école, une chance pour les filles de parents maghrébins. París: CIEMI-L'Harmattan.

Herrera, G. y Martínez, A. (2002). Género y migración en la región sur. Quito: FLACSO.

Pedone, C. (2003). "Tú siempre jalas a los tuyos»: Cadenas y redes migratorias de las familias ecuatorianas hacia España. Barcelona: Universidad Autónoma de Barcelona. Tesis doctoral. [www.tesisenxarxa.net, 20 de marzo de 2007]

- (2004). «La inmigración ecuatoriana: Pros y contras de una estrategia familiar para afrontar la crisis». En: CARRASCO, S. (coord.). Inmigración, contexto familiar y educación. Barcelona: Universitat Autònoma de Barcelona.

Pedreño, A. (2005). «Sociedades etnofragmentadas». En: Pedreño, A. y Hernández, M. (2005) (eds.). La condición inmigrante: Exploraciones e investigaciones desde la región de Murcia. Murcia: Universidad de Murcia.

- (2009) (coord.). "Que no sean como nosotros»: Trayectorias formativo-laborales de los hijos de familias inmigrantes en el campo murciano. Madrid: La Catarata (en proceso de publicación).

Portes, A. y Rumbaut, R. (2001). Legacies: The Story of the Immigrant Second Generation. Nueva York: Russell Sage Foundation.

RamíreZ, M.A. (1998). Migraciones, género e islam: Mujeres marroquíes en España. Madrid: Agencia Española de Cooperación Internacional (AECI).

RiESCO SANZ, A. (2003) «Enclaves y economías étnicas desde la perspectiva de las relaciones salariales». Cuadernos de Relaciones Laborales, 21 (2), 103-125.

Riesco Sanz, A. y CARrasco CARPIO, C. (2008). "Escuela, consumo y mercado laboral: La producción de la "juventud" entre los jóvenes de origen inmigrante». Revista de Educación, 345, 183-203. 
SAYAD, A. (1979). "Les enfants illégitimes». En: Actes de la Recherche en Sciences Sociales, 25, 61-81. Republicado en SAYAD, A. (1992). L'immigration ou les paradoxes de l'altérité. Bruselas: De Boeck.

SøRENSEN, N.N. (2004). «Globalización, género y migración transnacional: El caso de la diáspora dominicana». En: EsCRIVÁ, A. y RIBAS, N. (coords.). Migración y desarrollo. Córdoba: CSIC.

SuÁrez Navaz, L. y Crespo Bordonaba, P. (2007). "Familias en movimiento: El caso de las mujeres rumanas en España». Migraciones, 21, 234-257.

Tobío SOlER, C. y DíAZ GORFInKIEL, M. (2003). Las mujeres inmigrantes y la conciliación de la vida familiar y profesional. Madrid: Dirección General de la Mujer de la Comunidad de Madrid.

VALLET, L.-A. (1997). "Les élèves étrangers ou issus de l'immigration: les résultats du panel français dans une perspective comparative». En: AUBERT, F.; TrIPIER, M. y Vourc'H, F.: Jeunes issus de l'immigration: De l'école à l'emploi. París: CIEMIL'Harmattan.

WACQUANT, L. (2001). Parias urbanos: Marginalidad en la ciudad a comienzos del milenio. Buenos Aires: Manantial.

Zehraoui, A. (1999) (dir.). Familles d'origine algérienne en France: Étude sociologique des processus d'intégration. París: CIEMI-L'Harmattan.

Zeroulou, Z. (1985). «Mobilisation familiale et réussite scolaire». REMI: Revue Européenne des Migrations Internationales, 1 (2), 107-117. 